\title{
Renal Effects of Levosimendan: A Consensus Report
}

\author{
Mehmet B. Yilmaz • Elena Grossini • José C. Silva Cardoso • István Édes • Francesco Fedele • \\ Piero Pollesello • Matti Kivikko • Veli-Pekka Harjola • Julia Hasslacher • \\ Alexandre Mebazaa • Andrea Morelli • Jos le Noble • Anders Oldner • Ignacio Oulego Erroz • \\ John T. Parissis • Alexander Parkhomenko • Gerhard Poelzl • Sebastian Rehberg • \\ Sven-Erik Ricksten • Luís M. Rodríguez Fernández • Markku Salmenperä • Mervyn Singer • \\ Sascha Treskatsch • Bojan Vrtovec • Gerhard Wikström
}

Published online: 9 August 2013

(C) The Author(s) 2013. This article is published with open access at Springerlink.com

\begin{abstract}
Renal dysfunction is common in clinical settings in which cardiac function is compromised such as heart failure, cardiac surgery or sepsis, and is associated with high morbidity and mortality. Levosimendan is a calcium sensitizer and potassium channel opener used in the treatment of acute heart failure.
\end{abstract}

\author{
M. B. Yilmaz $(\bowtie)$ \\ Department of Cardiology, Cumhuriyet University School of \\ Medicine, Sivas, Turkey \\ e-mail: cardioceptor@gmail.com \\ E. Grossini \\ Laboratorio di Fisiologia, Dipartimento di Medicina Traslazionale, \\ Università degli Studi del Piemonte Orientale A. Avogadro, \\ Piemonte, Italy \\ e-mail: grossini@med.unipmn.it \\ J. C. Silva Cardoso \\ Faculdade de Medicina, Alameda Prof. Hernâni Monteiro, \\ Universidade do Porto, Porto, Portugal \\ e-mail: silvacardoso30@gmail.com \\ I. Édes \\ Institute of Cardiology, Medical and Health Science Center, \\ University of Debrecen, Debrecen, Hungary \\ e-mail: edesi@med.unideb.hu

\section{F. Fedele $\cdot$ A. Morelli} \\ Department of Cardiovascular, Respiratory, Nephrological, and \\ Geriatric Sciences, La Sapienza University of Rome, Rome, Italy \\ F. Fedele \\ e-mail: francesco.Fedele@uniroma1.it \\ A. Morelli \\ e-mail: andrea.morelli@uniroma1.it \\ P. Pollesello • M. Kivikko \\ Cardiology and Critical Care, Orion Pharma, Espoo, Finland \\ P. Pollesello \\ e-mail: piero.pollesello@orionpharma.com \\ M. Kivikko \\ e-mail: matti.kivikko@orionpharma.com
}

This review describes the effects of the inodilator levosimendan on renal function. A panel of 25 scientists and clinicians from 15 European countries (Austria, Finland, France, Hungary, Germany, Greece, Italy, Portugal, the Netherlands, Slovenia, Spain, Sweden, Turkey, the United Kingdom, and Ukraine) convened

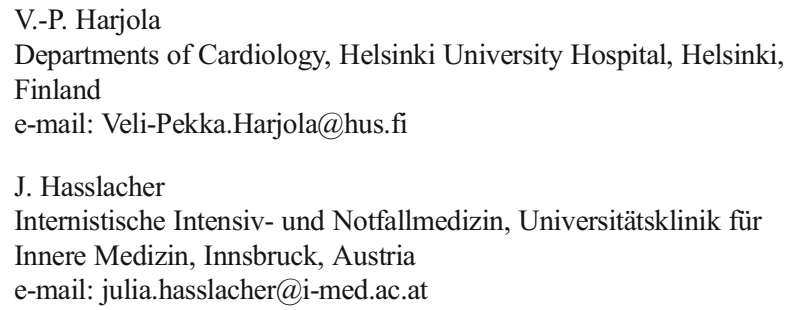

A. Mebazaa

Department of Anaesthesia and Intensive Care, INSERM UMR 942, Lariboisière Hospital, University of Paris, Paris, France

e-mail: alexandre.mebazaa@lrb.aphp.fr

\section{J. le Noble}

Department of Intensive Care, VieCuri Medical Center, Venlo,

The Netherlands

e-mail: jlenoble@viecuri.nl
A. Oldner
Department of Physiology \& Pharmacology, Section of
Anaesthesiology \& Intensive CareMedicine, Karolinska Institute,
Stockholm, Sweden
e-mail: anders.oldner@ki.se
I. Oulego Erroz • L. M. Rodríguez Fernández
Department of Pediatrics, Complejo Asistencial Universitario de
León, León, Spain
I. Oulego Erroz
e-mail: ignacio.oulego@gmail.com
L. M. Rodríguez Fernández
e-mail: luism@arrakis.es
J. T. Parissis
Heart Failure Unit, Attikon University Hospital, Athens, Greece
e-mail: jparissis@yahoo.com 
and reached a consensus on the current interpretation of the renal effects of levosimendan described both in non-clinical research and in clinical study reports. Most reports on the effect of levosimendan indicate an improvement of renal function in heart failure, sepsis and cardiac surgery settings. However, caution should be applied as study designs differed from randomized, controlled studies to uncontrolled ones. Importantly, in the largest HF study (REVIVE I and II) no significant changes in the renal function were detected. As it regards the mechanism of action, the opening of mitochondrial $\mathrm{K}_{\text {ATP }}$ channels by levosimendan is involved through a preconditioning effect. There is a strong rationale for randomized controlled trials seeking beneficial renal effects of levosimendan. As an example, a study is shortly to commence to assess the role of levosimendan for the prevention of acute organ dysfunction in sepsis (LeoPARDS).

Keywords Levosimendan $\cdot$ Renal dysfunction

$\begin{array}{ll}\text { Abbreviations } & \\ \text { HF } & \text { Heart failure } \\ \text { AHF } & \text { Acute heart failure } \\ \text { GFR } & \text { Glomerular filtration rate } \\ \text { eGFR } & \text { Estimated glomerular filtration rate } \\ \text { NYHA } & \text { New York Heart Association class } \\ \text { KATP channel } & \begin{array}{l}\text { Adenosine triphosphate-dependent } \\ \text { potassium channel }\end{array} \\ \text { I/R } & \text { Ischemia-reperfusion } \\ \text { NAG } & \text { N-acetyl- } \beta \text {-glucosaminidase } \\ \text { L-NAME } & \text { N } \omega \text {-nitro-L-arginine methyl ester } \\ \text { 5-HD } & \text { 5-hydroxydecanoate } \\ \text { RBF } & \text { Renal blood flow } \\ \end{array}$

A. Parkhomenko

Strazhesko Institute of Cardiology, National Scientific Centre, Kiev, Ukraine

e-mail: aparkhomenko@yahoo.com

G. Poelzl

Department of Cardiology, Medical University Innsbruck, Innsbruck, Austria

e-mail: gerhard.poelzl@uki.at

\section{S. Rehberg}

Department of Anesthesiology, Intensive Care and Pain Medicine, University of Muenster, Muenster, Germany

e-mail: Sebastian_Rehberg@ukmuenster.de

\section{S.-E. Ricksten}

Department of Cardiothoracic Anesthesia and Intensive Care, Sahlgrenska University Hospital, Gothenburg, Sweden

e-mail: sven-erik.ricksten@aniv.gu.se

\section{Salmenperä}

Department of Anesthesiology and Intensive Care Medicine, Helsinki University Hospital, Helsinki, Finland

e-mail: markku.salmenpera@hus.fi
CABG Coronary artery bypass grafting MAP Mean arterial pressure RPV Renal parenchymal volume

\section{Introduction}

Renal dysfunction is common in patients with heart failure (HF) [1] and other clinical settings in which cardiac function is compromised such as cardiac surgery or sepsis $[2,3]$ and is associated with high morbidity and mortality. Due to the complex interactions underlying this cardiorenal syndrome, the kidneys can be affected in both the short- and long-term. Elevations of serum urea and creatinine levels are often encountered in congestive HF, secondary to reductions in renal blood flow and/or elevations in central venous pressure leading to a reduction in glomerular filtration rate (GFR). Conversely, impaired renal function has a significant impact on the prognosis of patients with compromised heart function. For instance, in a broad spectrum of patients with chronic HF in the CHARM study [4], renal dysfunction was independently associated with increased risk of death, cardiovascular death, and hospitalization due to HF. In advanced chronic HF, renal impairment was a stronger predictor of mortality than either left ventricular ejection fraction or New York Heart Association class [5].

Levosimendan is a calcium sensitizer and adenosine triphosphate-dependent potassium $\left(\mathrm{K}_{\mathrm{ATP}}\right)$ channel opener developed for treating acute HF. Its positive inotropic, vasodilating and cardioprotective properties have been extensively investigated in experimental studies [6] and clinical trials [7] not only in the context of HF but also in surgery

M. Singer

Intensive Care Medicine, University College London, London, UK e-mail:m.singer@ucl.ac.uk

S. Treskatsch

Department of Anesthesiology and Intensive Care Medicine, Charité - University Medicine Berlin, Campus Charité Mitte and Campus Virchow-Klinikum, Berlin, Germany e-mail: sascha.treskatsch@charite.de

B. Vrtovec

Advanced Heart Failure and Transplantation Center, Department of Cardiology, Ljubljana University Medical Center, Ljubljana,

Slovenia

e-mail: bojan.vrtovec@gmail.com

G. Wikström

Kardiologkliniken, Akademiska Sjukhuset,

Uppsala, Sweden

e-mail: gerhard.wikstrom@medsci.uu.se 
settings and in critical care patients. Levosimendan increases myocardial contractility, reduces filling pressure, and dilates arterial, venous and coronary vessels [6]. In contrast to other inotropic agents, the enhanced cardiac contractility seen with levosimendan is not accompanied by large increases in oxygen consumption [8]. Levosimendan has an active metabolite, OR-1896, that has similar pharmacological properties to levosimendan. As this metabolite is formed and eliminated slowly, it offers at least 7 days of added benefit [9].

This paper examines available data on the effect of levosimendan on renal function also in comparison with other available inotropes and vasodilators.

\section{Methods}

In the systematic analysis of the literature data sources were PubMed, Index Medicus, Excerpta Medica, Reference Update, BIOSIS, Science Citation Index. Pertinent papers were independently identified by two trained investigators (updated October 20, 2012). Papers and abstracts found by searching (levosimendan AND (renal OR kidney*)) were selected according to the search strategy described in Figure 1. For the synthesis of the data a panel of 25 scientists and clinicians from 15 European countries (Austria, Finland, France, Hungary, Germany, Greece, Italy, Portugal, the Netherlands, Slovenia, Spain, Sweden, Turkey, the United Kingdom, and Ukraine) convened on October 25, 2012. The members of the panel were invited on the basis of their authorship of scientific papers which described the renal effects of levosimendan. Even if a paper did describe neutral or negative effects the first author was invited to attend and discuss his/her data. The panel reached a consensus on the current interpretation of the renal effects of levosimendan and its putative mechanisms of action.

\section{Evidence from Animal Models}

Pre-clinical data on renal perfusion effects are scant and sometimes contradictory (Table 1). In healthy dogs, levosimendan increased renal medullary blood flow [10], yet did not affect either the renal macro- or the micro-circulation under septic conditions in pigs and rabbits [11, 12]. In these studies, levosimendan improved cardiac function but also reduced arterial blood pressure; both of these factors will influence renal perfusion. Grossini et al. [13] investigated the renal effects of levosimendan in anesthetized pigs undergoing an ischemiareperfusion injury, under conditions of 'renal isolation'. Here, direct administration into the renal artery during $90 \mathrm{~min}$ of ischemia did not influence the subsequent change in renal blood flow on reperfusion [13].

The rationale for the use of levosimendan in lipopolysaccharide-induced acute renal failure was the assumption that calcium sensitization specifically offsets sepsis-induced reductions in myocardial function, and thus improves systemic and renal hemodynamics and mitigates the lipopolysaccharide-induced inflammatory state. Studies in endotoxemic mice [14] and ovine septic shock [15] found beneficial renal effects in conjunction with improved hemodynamics rather than immunomodulation [14]. In an endotoxemic pig model, where levosimendan did not improve hemodynamics, no beneficial effects on renal function were observed [15]. These findings are, however, not consistent.

In a study of porcine endotoxemia levosimendan markedly improved cardiac output and splanchnic but not renal blood flow [12].

Ischemia-reperfusion (I/R) injury in the kidneys is a significant problem in critically ill patients, e.g. after hemorrhage and/or trauma, as it is an important cause of acute renal failure due to oxidative, inflammatory and apoptotic mechanisms. I/ $\mathrm{R}$ injury can result in the development of a marked systemic inflammatory response and multiple organ dysfunction,
Fig. 1 Flow diagram for selection of the articles included in this systematic review

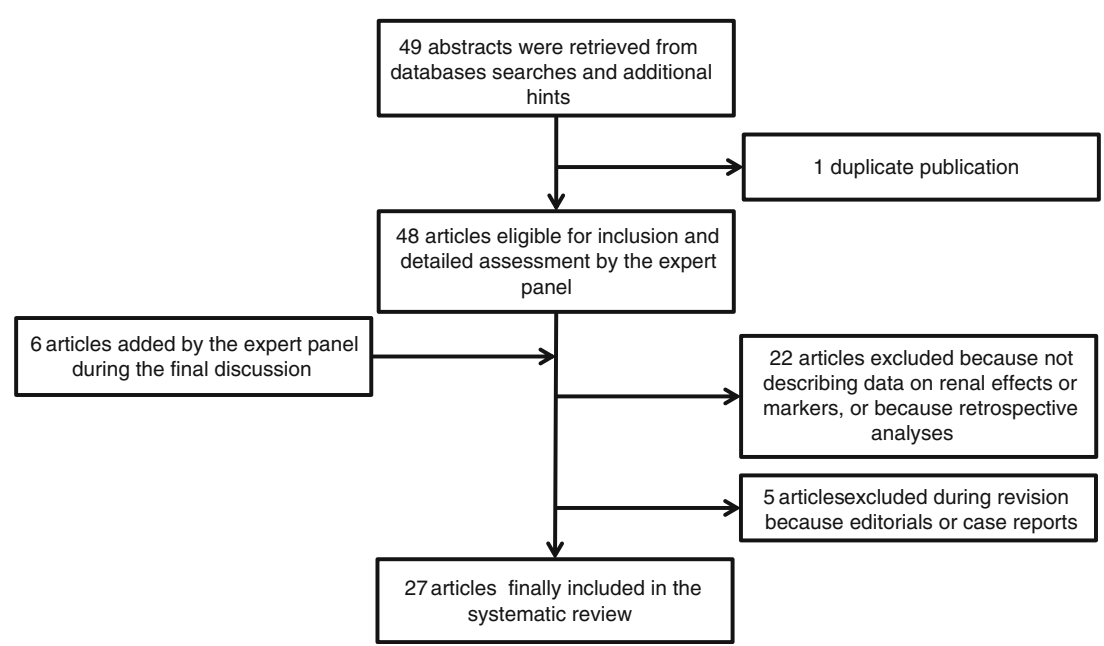


Table 1 Effects of levosimendan or its metabolite OR-1896 on renal tissue and/or function in in vivo animal experiments

\begin{tabular}{|c|c|c|c|c|}
\hline Study & $\begin{array}{l}\text { Animal } \\
\text { model }\end{array}$ & Disease model & Comparator & Main levosimendan effects on renal tissue and/or function \\
\hline Grossini [13] & Pig & Renal I/R & $\begin{array}{l}\text { Levosimendan without or } \\
\text { with Custodiol } ® \text { vs } \\
\text { placebo }\end{array}$ & $\begin{array}{l}\text { Better protection against renal I/R injury in terms of } \\
\text { antioxidant, anti-apoptotic and pro-survival actions, and } \\
\text { improvement of renal function (creatinine clearance, plasma } \\
\text { creatinine, microalbuminuria, albumin/creatinine ratio). Role } \\
\text { of mitochondrial } \mathrm{K}_{\mathrm{ATP}} \text { channels and NO }\end{array}$ \\
\hline Rehberg [42] & Sheep & Sepsis & $\begin{array}{l}\text { Vasopressin and } \\
\text { norepinephrine } \pm \\
\text { levosimendan }\end{array}$ & $\begin{array}{l}\text { Improved renal function (surrogate parameters: creatinine, } \\
\text { plasma urea, dieresis, urinary protein/creatinine ratio) }\end{array}$ \\
\hline Yakut [23] & Rabbit & Renal I/R & $\begin{array}{l}\text { Levosimendan vs placebo } \\
\text { or iloprost }\end{array}$ & More pronounced reduction in renal $I / R$ injury \\
\hline Zager [14] & Mouse & $\begin{array}{l}\text { Endotoxemic } \\
\text { acute renal } \\
\text { failure }\end{array}$ & Levosimendan vs placebo & $\begin{array}{l}\text { Protection against endotoxemic acute renal failure due to } \\
\text { vasoactive effects }\end{array}$ \\
\hline Faivre [11] & Rabbit & Sepsis & $\begin{array}{l}\text { Levosimendan with vasopressin } \\
\text { vs levosimendan with } \\
\text { norepinephrine }\end{array}$ & $\begin{array}{l}\text { No altered systolic or diastolic renal blood flow or cortical or } \\
\text { medullary perfusion }\end{array}$ \\
\hline Oldner [12] & Pig & Sepsis & Levosimendan vs placebo & Renal blood flow unaffected \\
\hline Pagel [10] & Dog & Healthy & $\begin{array}{l}\text { Levosimendan vs } \\
\text { pimobendan or milrinone }\end{array}$ & $\begin{array}{l}\text { Greater increase in blood flow to the renal medulla and } \\
\text { decreased } \\
\text { renal medullary and cortical vascular resistance }\end{array}$ \\
\hline Gecit [50] & Rat & $\begin{array}{l}\text { Enzyme } \\
\text { activities } \\
\text { in healthy } \\
\text { rats }\end{array}$ & Levosimendan vs placebo & Reduction of oxidative stress \\
\hline $\begin{array}{l}\text { Louhelainen } \\
\text { [24] }\end{array}$ & Rat & $\begin{array}{l}\text { Salt-induced } \\
\text { hypertension }\end{array}$ & OR 1896 vs placebo & No effects on albuminuria or tissue morphology \\
\hline Chew [51] & Pig & Sepsis & Levosimendan vs placebo & $\begin{array}{l}\text { No effects on renal and liver function (serum creatinine, urea, } \\
\text { bilirubin, AST, ALT) }\end{array}$ \\
\hline
\end{tabular}

$I / R$ ischemia/reperfusion; Custodiol ${ }^{\circledR}$ multi-organ histidine-tryptophan-ketoglutarate preservation solution; $N O$ nitric oxide; $A S T$ aspartate aminotransferase; $A L T$ alanine aminotransferase

leading to an approximate $30-40 \%$ mortality rate $[16,17]$. The anti-inflammatory and anti-apoptotic properties of levosimendan make it an interesting candidate for treatment of this condition. Indeed it has provided protection through a preconditioning effect [18-20] and a reduction in inflammatory and oxidative stress profiles [21, 22]. In a rabbit renal I/ $\mathrm{R}$ injury model, a levosimendan infusion commenced 30min pre-ischaemia provided similar renal protection as iloprost against oxidative stress [23]. Likewise, in a pig model, levosimendan infused into the renal artery during $90 \mathrm{~min}$ of ischemia followed by 120 -min of reperfusion provided renal protection with a reduction in renal damage (N-acetyl- $\beta$-glucosaminidase [NAG]), oxidative stress (malonyldialdehyde) and apoptosis [13]. Renal function was preserved to a higher degree, and cell survival and antioxidant systems were activated to a greater extent. These benefits could be prevented by pre-treatment with the nonspecific nitric oxide synthase blocker, $\mathrm{N}^{\omega}$-nitro-L-arginine methyl ester (L-NAME), or with the mitochondrial $\mathrm{K}_{\mathrm{ATP}}$ channel inhibitor, 5-hydroxydecanoate (5-HD). Finally, using a model of salt-sensitive hypertensive Dahl/Rapp rats, the levosimendan metabolite OR-1896 prevented salt-induced cardiovascular mortality and ameliorated cardiac hypertrophy and function, but without providing any significant renal protection [24].

\section{Consensus Opinion on Current Preclinical Data Regarding Renal Effects of Levosimendan}

Data obtained in pre-clinical studies suggest that the anti-oxidant and anti-apoptotic effects of levosimendan could be related to protection against renal ischemic reperfusion injury. As seen in the cardiac muscle, the opening of the mitochondrial $\mathrm{K}_{\text {ATP }}$ channels may be involved through a preconditioning effect, and nitric oxide may play a significant role. All in all, animal data on the effect of Levosimendan on renal function are not consistent. In fact, experimental data obtained in different renal injury models are quite different, but are still consistent within the individual models. In septic models there seems to be predominant improvements in hemodynamics by levosimendan, whereas the organ-protective effect of the drug dominates in case of $\mathrm{I} / \mathrm{R}$ injury. It should be noted there are no experimental data on renal effects in animal models of heart failure. Animal data on the 
effect of levosimendan on renal function do not provide definitive evidence as to whether the observed reno-protective effects are mediated by increases in renal perfusion and/or GFR, or other mechanisms.

\section{Clinical Evidence}

\section{Decompensated Heart Failure}

Renal effects of levosimendan have been evaluated in several clinical studies in patients with severe systolic HF. The LIDO randomized controlled trial compared levosimendan and dobutamine in patients with low-output HF [25]. Apart from an overall clinical outcome benefit, renal function (defined as a decrease in serum creatinine) improved over $24 \mathrm{~h}$ in the levosimendan arm, as compared to the control group ( -9 and $-1 \mu \mathrm{M} / 1$, respectively, $p=0,03)$. In parallel, the nonrandomized PORTLAND study assessed the efficacy and safety of levosimendan in the treatment of acute HF in everyday clinical practice [26]. Diuresis rapidly improved in previously oliguric patients after initiation of levosimendan, along with a reduction in serum creatinine levels that persisted on day five. We must highlight, however, that in the PORTLAND study there was not a control arm.

In a single-centre prospective study of patients with advanced chronic $\mathrm{HF}$ awaiting cardiac transplantation, at 3 months there was significant improvement in creatinine clearance in the levosimendan arm, with little or no change in the control group [27]. A fall in serum creatinine levels $\geq 0.5 \mathrm{mg} / \mathrm{dL}$ occurred in $50 \%$ of levosimendan patients, compared to $10 \%$ of controls $(p=0.005)$.

Yilmaz et al. [28] investigated 88 consecutive patients with acutely decompensated HF (NYHA III-IV) who required inotropic therapy. Patients were randomized to receive either levosimendan or dobutamine. While left ventricular ejection fraction increased significantly in both treatment groups, the levosimendan group showed significant improvement in GFR after $24 \mathrm{~h}(+15.3 \%)$, while the dobutamine arm showed no difference $(-1.33 \%)$. At $72 \mathrm{~h}$, GFR was significantly increased from baseline levels in levosimendan- ( $+45.45 \%)$, but not in dobutamine- $(+0.09 \%)$ treated patients, although both drugs improved 24-h urinary output. The same group also compared the effects of levosimendan and dobutamine on right ventricular function in 40 consecutive patients with severe chronic biventricular HF [29]. Again, levosimendan improved both 24-h urine output and creatinine levels, whereas dobutamine produced only a small increase in urine output and no improvement in creatinine levels. Levosimendan patients also required less diuretic therapy and were discharged sooner.

Zorlu et al. [30] studied the effect of levosimendan in patients with severe systolic heart failure and worsening renal function and subclassified the patients into those without and with worsening renal function, defined as an increase in serum creatinine $>0.3 \mathrm{mg} / \mathrm{dL}$. Levosimendan significantly improved renal function (creatinine, GFR) in those with worsening renal function but not in those with stable renal function.

Finally, Caira et al. [31] showed that levosimendan improves renal function, systemic and renal hemodynamic parameters in patients with acute heart failure and moderate renal impairment by measuring renal blood flow, glomerular filtration rate, blood urea nitrogen, creatinine, urinary output, sodium excretion and plasma sodium.

During a late revision of this text the results of the phase III studies REVIVE I and II were published [32] containing further data on the effect of levosimendan on renal function: worsening of renal function occurred in 12/350 patients in the levosimendan arms, and 16/350 patients in the placebo arm (n.s.), thus no significant improvement of renal function was found.

\section{Cardiac Surgery}

A limited number of clinical studies assessed the renal effects of levosimendan in the context of cardiac surgery. Bragadottir et al. [33] investigated the short-term effects of levosimendan on renal blood flow, GFR, renal oxygen consumption, and oxygenation in 30 patients with normal preoperative serum creatinine levels after uncomplicated surgery. Compared to placebo, levosimendan increased cardiac output, promoted renal vasodilatation and increased renal blood flow and GFR, suggestive of selective dilatation of pre-glomerular resistance vessels. The renal oxygen supply-demand relationship was however unaffected.

Levosimendan facilitated the weaning from the cardiopulmonary bypass in a placebo-controlled study in 60 patients with left ventricular ejection fraction $<50 \%$ undergoing coronary artery bypass grafting surgery [34]. In a substudy of the same population the postoperative renal function was assessed [35] and no significant differences between levosimendan and placebo groups were detected in terms of creatinine, cystatin $\mathrm{C}$ and urine $\mathrm{N}$-acetyl- $\beta$-glucosaminidase (NAG). Eight (26.6\%) levosimendan patients and 13 (43.3\%) placebo patients experienced renal incidents (as defined by the authors), though this difference did not reach statistical significance $(p=0.167)$.

Four additional studies on the use of levosimendan in cardiac surgery included some benefits on renal endpoints (mainly postoperative renal dysfunction or failure). Al-Shawaf et al. [36] studied type 2 diabetic patients with depressed myocardial function who underwent elective surgery for coronary artery disease. Among the postoperative events, renal dysfunction was noticed in $2 / 14$ patients treated with levosimendan vs $5 /$ 16 patients treated with milrinone. Alvarez et al. [37] compared levosimendan to dobutamine in cardiac surgery patients developing low cardiac output syndrome. The authors reported 1/15 renal failure in the levosimendan group vs $0 / 15$ in the 


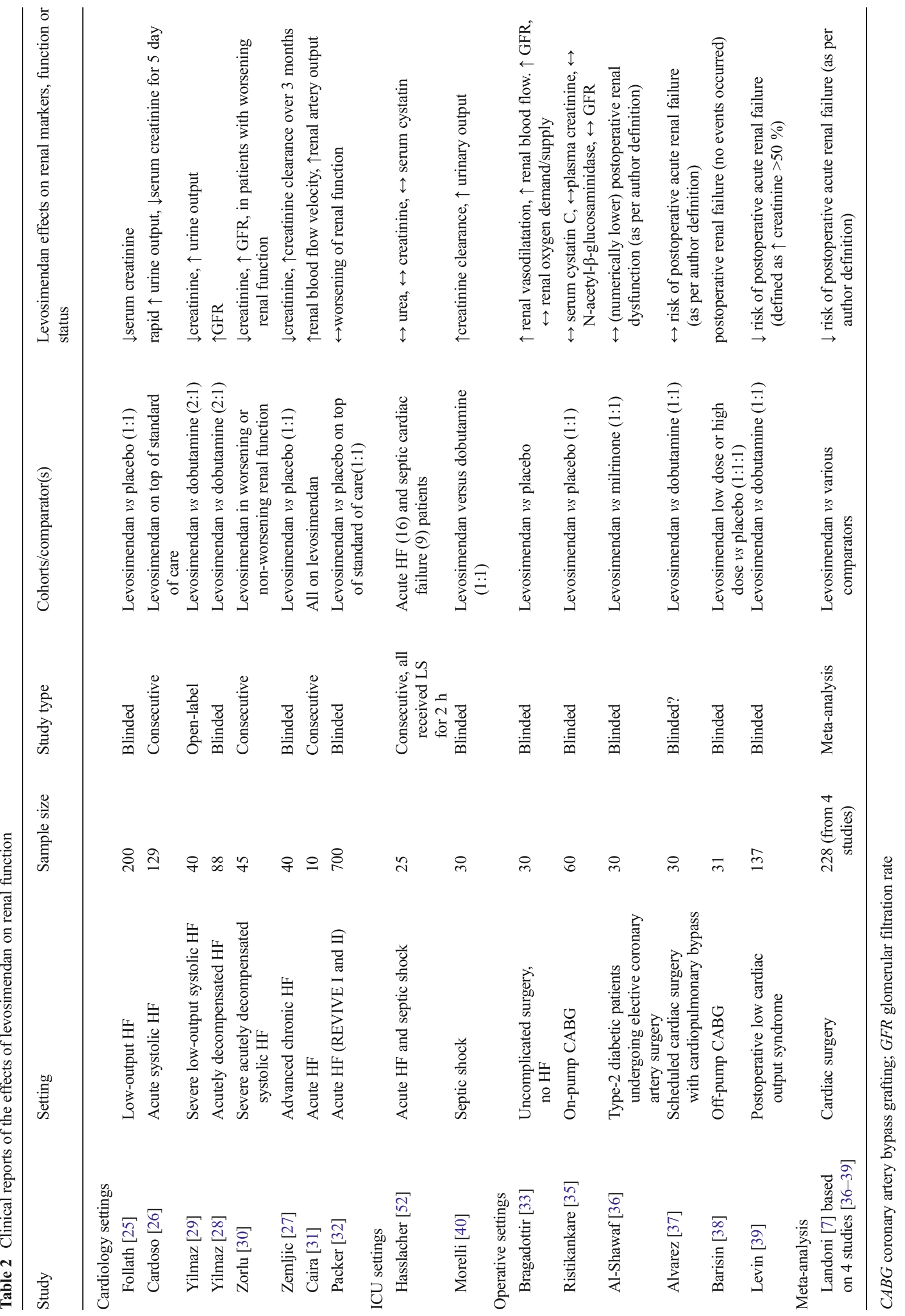


comparator group. Barisin et al. [38] did not notice any postoperative acute renal failure event in either the levosimendan or placebo arm when the treatment was administered preoperatively in patients undergoing off-pump CABG. Finally, Levin et al. [39] reported 5/69 and 21/68 episodes of renal failure in the levosimendan and dobutamine arms of their randomized study on the treatment of patients who develop post-operative low cardiac output syndrome after CABG with cardiopulmonary bypass. The data of these four studies are summarized in a recent meta-analysis by Landoni et al. [7].

\section{Sepsis}

A study by Morelli et al. reports data on the renal effect of levosimendan in septic patients. [40] Patients with persisting left ventricular dysfunction related to septic shock after $48 \mathrm{~h}$ of conventional treatment including dobutamine $(5 \mu \mathrm{g} / \mathrm{kg}$ per minute) were randomized after $48 \mathrm{~h}$ of conventional treatment to receive a 24 -h infusion of either levosimendan $(0.2 \mu \mathrm{g} / \mathrm{kg}$ per min, $n=15)$ or dobutamine $(5 \mu \mathrm{g} / \mathrm{kg}$ per min, $n=13)$. Among other effects, levosimendan increased gastric mucosal flow, creatinine clearance, and urinary output while it decreased lactate concentrations.

\section{Consensus Opinion on the Renal Effects of Levosimendan in a Clinical Setting}

Most reports on the effect of levosimendan indicate an improvement of renal function in heart failure, sepsis and cardiac surgery settings (Table 2). However, caution should be applied as study designs differed from randomized, controlled studies to uncontrolled ones. These studies are mainly confined to patients with severe systolic HF and some degree of renal dysfunction, and provide additional information on renal biomarkers and function. Importantly, in the largest HF study (REVIVE I and II) no significant changes in the renal function were detected. Data from the surgical setting are also heterogeneous, ranging from no effect in patients with normal renal function to clinical benefit in those requiring mechanical assist devices for post-cardiotomy HF. Larger studies in different clinical settings (mainly acute HF, septic shock, cardiac surgery) are warranted to clarify the renal effects of levosimendan.

\section{Potential Mechanisms of Renal Protection}

The $\mathrm{K}_{\text {ATP }}$ channel opening effects of levosimendan in vascular smooth muscle is linked to organ-preserving effects in several preclinical and clinical investigations [6]. As these channels are present in organ beds other than the myocardium, this mechanism may offer organ protection extending beyond the heart. Together with its hemodynamic effects, Morelli et al. [41] suggested levosimendan may also be protective for lung, kidney, liver, gastrointestinal mucosa, brain and vascular endothelium.

Timely intervention with levosimendan may reverse the ongoing processes of renal dysfunction through several protective mechanisms involving macro- or microcirculation. Renal blood flow depends on renal vascular resistance, as well as, arterial and venous pressures. Of note, central venous pressure is an important independent predictor of eGFR in patients with HF [42].
Fig. 2 Differential effects of renal vasodilators on preglomerular (afferent arteriole) and postglomerular (efferent arteriole) vascular resistance sections. $R B F$ renal blood flow; $M A P$ mean arterial pressure; $R P V$ renal parenchymal volume; $G F R$ glomerular filtration rate

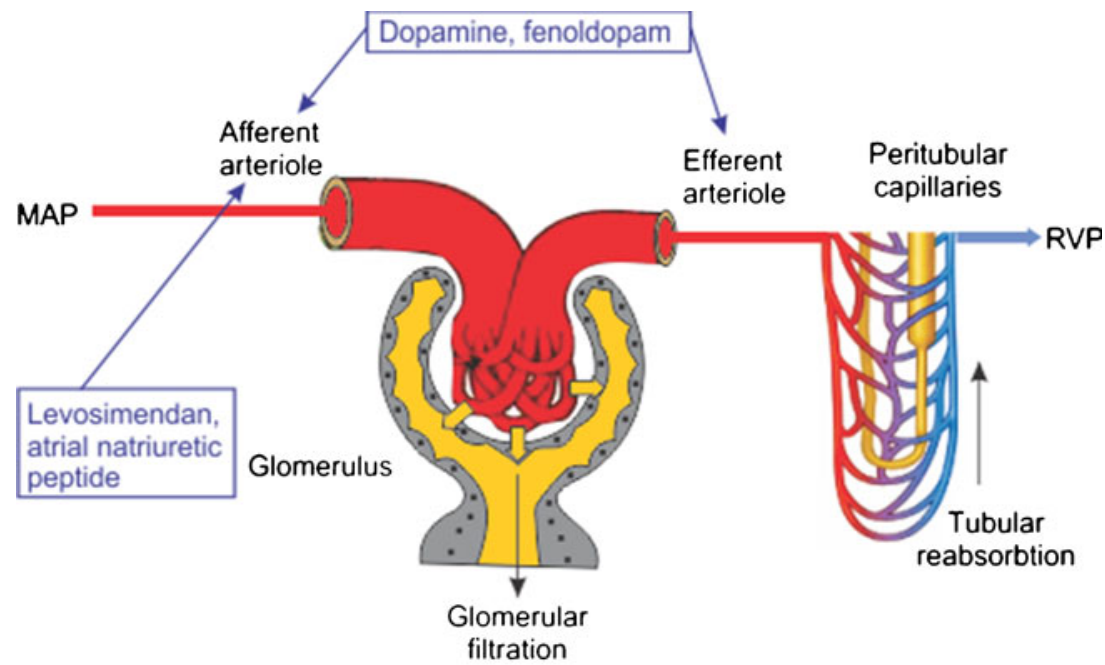

Predominant afferent vasodilation: RBF $\uparrow$; GFR $\uparrow$

Predominant efferent vasodilation: RBF $\uparrow$; GFR

Afferent + efferent vasodilation: RBF $\uparrow \uparrow ;$ GFR $\uparrow \downarrow$ 
When compared to traditional inotropes, levosimendan provides functional improvement of the right ventricle and significant reductions in right-sided pressures, including central venous and pulmonary artery wedge pressures [43-45]. This potentially alleviates the increased renal vein pressure that may impair renal function through a decreased perfusion pressure and a decrease in GFR.

Furthermore, Bragadottir et al. [33] found that levosimendan induced a preglomerular vasodilation (with an increase in both RBF and GFR), suggesting that the potential beneficial renal effects of levosimendan in patients with heart failure and impaired renal function, may not only be caused by an increase in cardiac output, but also by a specific renal vasodilatory action. In fact, $\mathrm{K}_{\text {ATP }}$ channels are also present in afferent arterioles [46] and may play a role in the effects of levosimendan on renal blood flow (see Fig. 2). In contrast, in cardiac surgery patients, dopamine dilates both pre- and postglomerular resistance vessels, with a pronounced increase in renal blood flow but with no change in GFR [47].

With regard to the microcirculation, levosimendan may augment renal perfusion via vasodilatation arising from its $\mathrm{K}_{\mathrm{ATP}}$ channel agonism. Furthermore, it may reverse angiotensin-2mediated mesangial cell contraction [14], thereby increasing glomerular capillary surface area [48]. This provides a further rationale for the use of levosimendan in septic shock where renal vasoconstriction is mediated at least in part by angiotensin-2 [40]. Other potentially beneficial mechanisms within the kidney relate to preconditioning, anti-inflammatory and anti-apoptotic effects [6].

\section{Future Studies}

The panel agreed that it would be useful, although a very demanding task, to compare systematically the renal effects of other i.v. drugs used in acute cardiac care (in all settings) such as recombinant natriuretic peptides, nitrates, other $\mathrm{K}_{\mathrm{ATP}}$ channels openers, catecholamines, and phosphodiesterase inhibitors (see the recent data associating milrinone to an increase of acute kidney injury risk in cardiac surgery [49]).

Ideally, large randomized controlled trials seeking beneficial renal effects of levosimendan in different clinical settings should be performed.

In this regard, it is worth to mention that a 500-patient study sponsored by the NIHR-EME program is shortly to commence in the UK (led by Dr Anthony Gordon in conjunction with the Imperial Clinical Trials Unit) assessing the role of Levosimendan for the Prevention of Acute oRgan Dysfunction in Sepsis (LeoPARDS). This double-blind randomised placebocontrolled trial will test if levosimendan, when added to normal care, can reduce multiple organ failure, which will then hopefully lead to better outcomes and survival rates for patients.
Acknowledgments We thank Ms. Tiina Pettersson for contribution in formatting the text.

Funding Acknowledgments This study did not receive any financial support apart for the logistic expenses related to the organization of the consensus meeting in Munich on October 25, 2012 which were taken care by Orion Pharma. For their role of chairmen of the meeting, Drs. Mebazaa, Morelli, and Singer received an honorarium by Orion Pharma. In the past 5 years Drs. Yilmaz, Grossini, Édes, Fedele, Harjola, Mebazaa, Morelli, Parissis, Parkhomenko, Poelzl, Salmenperä, Singer, and Wikström received honoraria by Orion Pharma for lecturing or chairing sessions on the use of levosimendan at various national and international congresses. Orion Pharma follows the code of conduct of the European Federation of Pharmaceutical Industries and Associations (EFPIA).

Open Access This article is distributed under the terms of the Creative Commons Attribution License which permits any use, distribution, and reproduction in any medium, provided the original author(s) and the source are credited.

\section{References}

1. Metra M, Cotter G, Gheorghiade M, Dei Cas L, Voors AA. The role of the kidney in heart failure. Eur Heart J. 2012;33:2135-42.

2. Kallel S, Triki Z, Abdenadher M, Frikha I, Jemel A. Karoui a [acute renal failure after cardiac surgery: evaluation of the RIFLE criteria]. Nephrol Ther. 2013;9:108-14.

3. Oppert M, Engel C, Brunkhorst F-M, Bogatsch H, Reinhart K, Frei U, et al. Acute renal failure in patients with severe sepsis and septic shock-a significant independent risk factor for mortality: results from the German Prevalence Study. Nephrol Dial Transplant. 2008;23:904 9.

4. Hillege HL, Nitsch D, Pfeffer MA, Swedberg K, McMurray JJV, Yusuf S, et al. Renal function as a predictor of outcome in a broad spectrum of patients with heart failure. Circulation. 2006;113:671-8.

5. Hillege HL, Girbes AR, de Kam PJ, Boomsma F, de Zeeuw D, Charlesworth $\mathrm{A}$, et al. Renal function, neurohormonal activation, and survival in patients with chronic heart failure. Circulation. 2000;102:203-10.

6. Papp Z, Edes I, Fruhwald S, De Hert SG, Salmenpera M, Leppikangas $\mathrm{H}$, et al. Levosimendan: molecular mechanisms and clinical implications: consensus of experts on the mechanisms of action of levosimendan. Int J Cardiol. 2012;159:82-7.

7. Landoni G, Mizzi A, Biondi-Zoccai G, Bruno G, Bignami E, Corno $\mathrm{L}$, et al. Reducing mortality in cardiac surgery with levosimendan: a meta-analysis of randomized controlled trials. J Cardiothorac Vasc Anesth. 2010;24:51-7.

8. Nieminen MS, Pollesello P, Vajda G, Papp Z. Effects of levosimendan on the energy balance: preclinical and clinical evidence. J Cardiovasc Pharmacol. 2009;53:302-10.

9. Kivikko M, Lehtonen L, Colucci WS. Sustained hemodynamic effects of intravenous levosimendan. Circulation. 2003;107:81-6.

10. Pagel PS, Hettrick DA, Warltier DC. Influence of levosimendan, pimobendan, and milrinone on the regional distribution of cardiac output in anaesthetized dogs. Br J Pharmacol. 1996;119:609-15.

11. Faivre V, Kaskos H, Callebert J, Losser M-R, Milliez P, Bonnin P, et al. Cardiac and renal effects of levosimendan, arginine vasopressin, and norepinephrine in lipopolysaccharide-treated rabbits. Anesthesiology. 2005;103:514-21.

12. Oldner A, Konrad D, Weitzberg E, Rudehill A, Rossi P, Wanecek M. Effects of levosimendan, a novel inotropic calcium-sensitizing drug, in experimental septic shock. Crit Care Med. 2001;29:2185-93. 
13. Grossini E, Molinari C, Pollesello P, Bellomo G, Valente G, Mary D, et al. Levosimendan protection against kidney ischemia/reperfusion injuries in anesthetized pigs. J Pharmacol Exp Ther. 2012;342:37688 .

14. Zager RA, Johnson AC, Lund S, Hanson SY, Abrass CK. Levosimendan protects against experimental endotoxemic acute renal failure. Am J Physiol Renal Physiol. 2006;290:F1453-62.

15. Rehberg S, Ertmer C, Vincent J-L, Spiegel H-U, Kohler G, Erren M, et al. Effects of combined arginine vasopressin and levosimendan on organ function in ovine septic shock. Crit Care Med. 2010;38:2016-23.

16. Neary P, Redmond HP. Ischemia-reperfusion injury and the systemic inflammatory response syndrome. In: Grace PA, Mathie RT, editors. Ischemia-reperfusion injury. London: Blackwell Science; 1999. p. 123-36.

17. Sucu N, Unlu A, Tamer L, Aytacoglu B, Coskun B, Bilgin R, et al. Effects of trimetazidine on tissue damage in kidney after hindlimb ischemia-reperfusion. Pharmacol Res. 2002;46:345-9.

18. Caimmi PP, Kapetanakis EI, Beggino C, Molinari C, Giustini G, Crosio E, et al. Management of acute cardiac failure by intracoronary administration of levosimendan. J Cardiovasc Pharmacol. 2011;58:246-53.

19. Kersten JR, Montgomery MW, Pagel PS, Warltier DC. Levosimendan, a new positive inotropic drug, decreases myocardial infarct size via activation of K(ATP) channels. Anesth Analg. 2000;90:5-11.

20. Soeding PF, Crack PJ, Wright CE, Angus JA, Royse CF. Levosimendan preserves the contractile responsiveness of hypoxic human myocardium via mitochondrial K(ATP) channel and potential pERK 1/2 activation. Eur J Pharmacol. 2011;655:59-66.

21. Avgeropoulou C, Andreadou I, Markantonis-Kyroudis S, Demopoulou M, Missovoulos P, Androulakis A, et al. The $\mathrm{Ca} 2+$-sensitizer levosimendan improves oxidative damage, BNP and pro-inflammatory cytokine levels in patients with advanced decompensated heart failure in comparison to dobutamine. Eur J Heart Fail. 2005;7:882-7.

22. Uberti F, Caimmi PP, Molinari C, Mary D, Vacca G, Grossini E. Levosimendan modulates programmed forms of cell death through K(ATP) channels and nitric oxide. J Cardiovasc Pharmacol. 2011;57:246-58.

23. Yakut N, Yasa H, Bahriye Lafci B, Ortac R, Tulukoglu E, Aksun M, et al. The influence of levosimendan and iloprost on renal ischemiareperfusion: an experimental study. Interact Cardiovasc Thorac Surg. 2008;7:235-9.

24. Louhelainen M, Merasto S, Finckenberg P, Vahtola E, Kaheinen P, Leskinen H, et al. Effects of calcium sensitizer OR-1986 on a cardiovascular mortality and myocardial remodelling in hypertensive Dahl/Rapp rats. J Physiol Pharmacol. 2009;60:41-7.

25. Follath F, Cleland JGF, Just H, Papp JGY, Scholz H, Peuhkurinen K, et al. Efficacy and safety of intravenous levosimendan compared with dobutamine in severe low-output heart failure (the LIDO study): a randomised double-blind trial. Lancet. 2002;360:196-202.

26. Silva-Cardoso J, Ferrreira J, Oliveira-Soares A, Martins-de-Campos $\mathrm{J}$, Fonseca C, Lousada N, et al. Effectiveness and safety of levosimendan in clinical practice. Rev Port Cardiol. 2009;28:143-53.

27. Zemljic G, Bunc M, Yazdanbakhsh AP, Vrtovec B. Levosimendan improves renal function in patients with advanced chronic heart failure awaiting cardiac transplantation. J Card Fail. 2007;13:41721.

28. Yilmaz MB, Yalta K, Yontar C, Karadas F, Erdem A, Turgut OO, et al. Levosimendan improves renal function in patients with acute decompensated heart failure: comparison with dobutamine. Cardiovasc Drugs Ther. 2007;21:431-5.

29. Yilmaz MB, Yontar C, Erdem A, Karadas F, Yalta K, Turgut OO, et al. Comparative effects of levosimendan and dobutamine on right ventricular function in patients with biventricular heart failure. Heart Vessels. 2009;24:16-21.

30. Zorlu A, Yucel H, Yontar OC, Karahan O, Tandogan I, Katrancioglu $\mathrm{N}$, et al. Effect of levosimendan in patients with severe systolic heart failure and worsening renal function. Arq Bras Cardiol. 2012;98:537-43.

31. Caira C, Brasolin B, Maestrini V, Scardala R, Orvieto G, Mancone $\mathrm{M}$, et al. 475 Effects of Levosimendan on renal function and renal hemodynamic parameters in patients with acute heart failure. Eur J Heart Fail Suppl. 2007;6:103.

32. Packer M, Colucci W, Fisher L, Massie WM, Teerlink JR, Young J, et al For the REVIVE heart failure study group. Effect of levosimendan on the short-term clinical course of patients with acutely decompensated heart failure. JACC Heart Fail. 2013;1:103-11.

33. Bragadottir G, Redfors B, Ricksten SE. Effects of levosimendan on renal blood flow, glomerular filtration rate, renal oxygen consumption and oxygenation after cardiac surgery: a randomized controlled study. Crit Care Med, In press.

34. Eriksson HI, Jalonen JR, Heikkinen LO, Kivikko M, Laine M, Leino $\mathrm{KA}$, et al. Levosimendan facilitates weaning from cardiopulmonary bypass in patients undergoing coronary artery bypass grafting with impaired left ventricular function. Ann Thorac Surg. 2009;87:44854.

35. Ristikankare A, Poyhia R, Eriksson H, Valtonen M, Leino K, Salmenpera M. Effects of levosimendan on renal function in patients undergoing coronary artery surgery. J Cardiothorac Vasc Anesth. 2012;26:591-5.

36. Al-Shawaf E, Ayed A, Vislocky I, Radomir B, Dehrab N, Tarazi R. Levosimendan or milrinone in the type 2 diabetic patient with low ejection fraction undergoing elective coronary artery surgery. $\mathrm{J}$ Cardiothorac Vasc Anesth. 2006;20:353-7.

37. Alvarez J, Taboada M, Rodriguez J, Caruezo V, Bouzada M, Campana $\mathrm{O}$, et al. [Hemodynamic effects of levosimendan following cardiac surgery]. Rev Esp Anestesiol Reanim. 2005;52:38994 .

38. Barisin S, Husedzinovic I, Sonicki Z, Bradic N, Barisin A, Tonkovic D. Levosimendan in off-pump coronary artery bypass: a four-times masked controlled study. J Cardiovasc Pharmacol. 2004;44:703-8

39. Levin RL, Degrange MA, Porcile R, Salvagio F, Blanco N, Botbol $\mathrm{AL}$, et al. [The calcium sensitizer levosimendan gives superior results to dobutamine in postoperative low cardiac output syndrome]. Rev Esp Cardiol. 2008;61:471-9.

40. Morelli A, De Castro S, Teboul J-L, Singer M, Rocco M, Conti G, et al. Effects of levosimendan on systemic and regional hemodynamics in septic myocardial depression. Intensive Care Med. 2005;31:638-44.

41. Morelli A, Ertmer C, Pietropaoli P, Westphal M. Reducing the risk of major elective non-cardiac surgery: is there a role for levosimendan in the preoperative optimization of cardiac function? Curr Drug Targets. 2009; 10:863-71.

42. Damman K, van Deursen VM, Navis G, Voors AA, van Veldhuisen DJ, Hillege HL. Increased central venous pressure is associated with impaired renal function and mortality in a broad spectrum of patients with cardiovascular disease. J Am Coll Cardiol. 2009;53:582-8.

43. Parissis JT, Paraskevaidis I, Bistola V, Farmakis D, Panou F, Kourea $\mathrm{K}$, et al. Effects of levosimendan on right ventricular function in patients with advanced heart failure. Am J Cardiol. 2006;98:1489 92.

44. Poelzl G, Zwick RH, Grander W, Metzler B, Jonetzko P, Frick M, et al. Safety and effectiveness of levosimendan in patients with predominant right heart failure. Herz. 2008;33:368-73.

45. Russ MA, Prondzinsky R, Carter JM, Schlitt A, Ebelt H, Schmidt H, et al. Right ventricular function in myocardial infarction complicated by cardiogenic shock: improvement with levosimendan. Crit Care Med. 2009;37:3017-23.

46. Lorenz JN, Schnermann J, Brosius FC, Briggs JP, Furspan PB. Intracellular ATP can regulate afferent arteriolar tone via ATPsensitive K+channels in the rabbit. J Clin Invest. 1992;90:733-40. 
47. Redfors B, Bragadottir G, Sellgren J, Sward K, Ricksten SE. Dopamine increases renal oxygenation: a clinical study in postcardiac surgery patients. Acta Anaesthesiol Scand. 2010;54:18390 .

48. Appel RG, Wang J, Simonson MS, Dunn MJ. A mechanism by which atrial natriuretic factor mediates its glomerular actions. Am J Physiol. 1986;251:1036-42.

49. Morgan CJ, Gill PJ, Lam S, Joffe AR. Peri-operative interventions, but not inflammatory mediators, increase risk of acute kidney injury after cardiac surgery: a prospective cohort study. Intensive Care Med. 2013;39:934-41.
50. Gecit I, Kavak S, Yuksel MB, Basel H, Bektas H, Gumrukcuoglu HA et al. Effect of short-term treatment with levosimendan on oxidative stress in renal tissues of rats. Toxicol Ind Health. 2012.

51. Chew MS, Hawthorne WJ, Bendall J, Whereat S, Huang S, Ting I, et al. No beneficial effects of levosimendan in acute porcine endotoxaemia. Acta Anaesthesiol Scand. 2011;55:851-61.

52. Hasslacher J, Bijuklic K, Bertocchi C, Kountchev J, Bellmann R, Dunzendorfer $\mathrm{S}$, et al. Levosimendan inhibits release of reactive oxygen species in polymorphonuclear leukocytes in vitro and in patients with acute heart failure and septic shock: a prospective observational study. Crit Care. 2011;15:R166. 